\title{
RIQUEZA INVISÍVEL: O TRABALHO ESSENCIALMENTE FEMININO NA PRODUÇÃO DE SEMIJOIAS EM LIMEIRA, SÃO PAULO
}

\author{
Marta Mesquita Silva Viganô ${ }^{1}$ \\ Sandra Francisca Bezerra Gemma ${ }^{2}$ \\ Marta Fuentes-Rojas ${ }^{3}$
}

Resumo: Objetivo: desvelar a natureza do trabalho realizado em fábricas de semijoias na cidade de Limeira, São Paulo, e sua relação com cenário social de trabalho informal presente na cidade. Método: três fábricas da cidade foram estudadas por meio de uma adaptação do método Análise Ergonômica do Trabalho (AET). Resultados $e$ discussão: Além da caracterização geral dos processos e atividades desenvolvidas nas fábricas, o trabalho feminino exercido em vendas permitiu explicitar a diversidade e as contradições existentes e apontar as conexões da produção fabril com o cenário mais amplo do município, bem como desvelar a relação da produção em escala com o trabalho artesanal e criativo. Evidenciou-se que esse trabalho inclui desde a criação e

\footnotetext{
${ }^{1}$ Graduação em Fisioterapia pela Pontifícia Universidade Católica de Campinas (2007) e pós-graduação lato sensu em Fisioterapia do Trabalho pelo grupo CBES, São Paulo (2009). Faz parte do grupo de pósgraduação stricto sensu da Unicamp, campus Limeira, Faculdade de Ciências Aplicadas, no Laboratório de Ergonomia.

${ }^{2}$ Especialista em Ergonomia pela Engenharia de Produção da Escola Politécnica da USP (2001), com Doutorado (2008) e Mestrado (2004) em Engenharia Agrícola na temática de Ergonomia pela Universidade Estadual de Campinas. Tem experiência na área de Ergonomia, principalmente em Ergonomia da Atividade/AET (Análise Ergonômica do Trabalho); Saúde e Trabalho; Agricultura Orgânica e Complexidade. Professora Doutora (MS3.2) da Faculdade de Ciências Aplicadas, UNICAMP-Limeira, na área de engenharia em Ergonomia, Saúde e Trabalho. É professora plena do ICHSA - Curso de Mestrado Interdisciplinar em Ciências Humanas e Sociais Aplicadas da FCA-UNICAMP na linha de pesquisa Sustentabilidade e proteção social.

${ }^{3}$ Possui graduação em Psicologia - Fundacão Konrad Lorenz (1989) Bogotá-Colômbia, Mestrado em Educação pela Universidade Estadual de Campinas (1996) e Doutorado em Saúde Coletiva pela Universidade Estadual de Campinas (2001). Pós-doutorado junto ao Núcleo de Estudos da Mulher e Relações Sociais de Gênero - NEMGE, da Universidade de São Paulo - USP. Tem participado como docente dos cursos de Psicologia e de Enfermagem. Ministrado aulas e supervisionado estágios na área de Saúde Coletiva e Clinica Psicológica na Abordagem Humanista. Atuando principalmente nos seguintes temas: educação em saúde, saúde coletiva, trabalho comunitário, psicologia comunitária, terapia comunitária, saúde do adolescente, qualidade de vida, relações, grupos e instituições, terapia centrada na pessoa. Na pós-graduação no curso de saúde da família e na extensão no curso de formação de terapeutas comunitários. Atualmente, docente da Faculdade de Ciências Aplicadas da Universidade Estadual de Campinas - UNICAMP- Limeira.
} 
montagem de produtos, passando por serviços e pós-vendas, bem como gestão de custos e logística, assim como de trabalhadores formais e terceirizados. Para além do esperado de uma produção metalúrgica em larga escala, se observa a conciliação com uma manufatura customizada, pouco automatizada, dependente de constantes manobras entre produção e clientes, altamente atrelada ao conhecimento e experiência das trabalhadoras. A real beleza e riqueza se desvela no trabalho invisível dessas mulheres que fazem arte no contexto desfavorável da produção em massa.

Palavras-chave: ergonomia da atividade; análise ergonômica do trabalho; semijoias; trabalho feminino

Abstract: Objective: to unveil the nature of the work in semi-jewel factories in the city of Limeira, São Paulo, and its connection to the social context of informal work that exists in the city. Methods: three factories in the city of Limeira were studied with an adaptation of the Ergonomic Work Analysis (EWA) method. Results and conclusions: Limeira, São Paulo, is officially Brazil's semi-jewel capital, however, its prosperous economic results contrast with the negative social and environmental externalities associated with this sector. In addition to the characterization of the processes and activities carried out in the factories, the female work observed in sales department made it possible to show the diversity and contradictions in this work and to indicate connections of the factory production with the wider scenario of the city, and also to unveil the large-scale production combined with artisanal and creative work. It has been seen that this work contents from the creation and assembly of products, throughout services and after sales, up to cost and logistics management, as well as formal and outsourced workers. Beyond expected of a large-scale metallurgical production, we could observe the conciliation with a custom manufacturing, not automated, dependent on constant maneuvers and management between production and customers, highly linked to the knowledge and experience of the workers. Real beauty and richness are revealed in the invisible and undervalued work of these women who still manage to make art in the unfavorable context of mass production. 
Keywords: activity ergonomics; ergonomic work analysis; semi-jewel; female work

\section{Introdução}

A cidade de Limeira situada no estado de São Paulo é conhecida como a Capital Nacional da Joia Folheada ${ }^{1}$, chamando a atenção pela intensa produção e comercio, mas também por algumas questões sociais e ambientais negativas (Ferreira, 2005; Vilela e Ferreira, 2008).

O setor de joias e semijoias é considerado polo no Brasil em virtude de seu perfil exportador e importância no cenário nacional e internacional. Em 2018, o setor de Gemas, Joias e Bijuterias e Relógios registrou faturamento de $\mathrm{R} \$ 13,8$ bilhões, dos quais $9,4 \%$ em bijuterias e folheados (MME, 2018). Até o ano de 2015, o Brasil ocupou o $14^{\circ}$ lugar dentre os principais países exportadores de folheados (IBGM, 2015).

As informações sobre esse complexo setor vêm prontamente acompanhadas de discussões sobre rendimentos e competição, entre outras características de mercado (SENAI, 2011). Entretanto, o que não se anuncia é que este setor detém uma manufatura bem específica, pouco automatizada e que se mescla à arte. As questões ligadas ao trabalho informal e infantil têm sido estudadas, mas pouco se sabe sobre o trabalho em si, sua natureza, seu conteúdo, bem como de que maneira e sob quais condições ele é realizado pelos(as) trabalhadores(as).

Numa pesquisa realizada em 2005 com estudantes do Ensino Fundamental e Médio da rede Estadual de Ensino de Limeira, foi constatado que $27 \%$ dos estudantes (8.340 indivíduos) realizavam trabalhos com semijoias e bijuterias dentro dos domicílios, o que acarretava situação de trabalho infantil ${ }^{2}$. Além disso, foram identificados elementos químicos no esgoto urbano, relacionados com os banhos de galvanoplastia nas peças das joias e bijuterias (Vilela e Ferreira, 2008).

Em 2017, Vendramin identificou que na região sul e central de Limeira, $28,50 \%$ dos estudantes trabalhavam na produção de semijoias e na região sul essa porcentagem foi de $39,30 \%$, na faixa etária de 08 a 12 anos (Vendramin, 2017).

Diante disso, nessa pesquisa objetivamos desvelar alguns aspectos do trabalho do principal setor produtivo da 
cidade de Limeira, focando em sua natureza e determinantes para compreender suas principais características e como elas simultaneamente se relacionam com o suposto sucesso e o conflitante contexto social.

Este estudo foi aprovado pelo Comitê de Ética em Pesquisa da Unicamp

CAAE: 45799615.5.0000.5404. Foi utilizado o método da Análise Ergonômica do Trabalho (AET) (Guérin et al. 2001; Sznelwar, 2006; Ferreira, 2015; Ferreira, 2015a ; Ferrreira, 2015b) que além de ser um método de pesquisa indutivo, tem como principais pressupostos a participação dos sujeitos e o estudo de situações reais de trabalho numa perspectiva interdisciplinar (Guérin et al. 2001; Sznelwar, 2006). Este método foi adaptado e aplicado em três fábricas de semijoias de Limeira.

Nesse processo foi escolhida uma das fabricas como representante para constituir um micro ecossistema de decisões e ações que permitiram compreender a forma como se realizam as atividades nessas fabricas.

Percebeu-se que a rotina dessas fábricas é marcada por produção de acordo com a demanda, por pedidos de produtos customizados não apenas em suas características de desenho, tais como, cores, pedras e formas, mas também, na dimensão de volumes, podendo ser requisitados de dezenas a milhares de produtos variados. No entanto, observamos que mesmo com o peso das regras, a estandardização do produto e a grande demanda a cada peça concluída se revelava a criatividade e o registro do Ser de cada trabalhador(a) (Bachelard,1985).

\section{O Trabalho Nas Fábricas De} Semijoias Em Limeira

A realização de uma adaptação da AET em cada fábrica trouxe a possibilidade de conhecer características singulares do trabalho em cada uma delas, além de percepções do setor e de forma mais geral as exigências do mercado e do próprio município.

No total, foram realizadas 52 visitas às três fábricas, denominadas A, $\mathrm{B}$ e $\mathrm{C}$ no período de dois anos e meio (2015 a 2018), durante o qual fomos construindo as problemáticas e planos de análise, juntamente com os interlocutores e atores do trabalho, por meio de entrevistas abertas, observações e registros em diário de campo. 
Em relação ao número de efetivos a fábrica A possuía 53 empregados (40 mulheres e 13 homens), a fábrica $\mathrm{B}$ contava com 42 empregados (32 mulheres e 10 homens) e na fábrica C existiam 30 funcionários (14 mulheres e 16 homens). Quanto ao tempo de empresa, nas três fábricas a maioria deles tem entre 1 a 3 anos, com exceção da função de vendas, exercida exclusivamente por mulheres entre 10 anos a 30 anos de experiência. A divisão sexual do trabalho (Hirata e Kergoat, 2007; Kergoat, 2009) se mostra visível nesse setor, em particular pelo que se atribui socialmente às características do trabalho feminino (Vidal e Silvany Neto, 2003).

As análises foram realizadas paralelamente nas três fábricas e foi necessário, em determinado momento, aprofundar a coleta de dados em relação ao conteúdo do trabalho em uma das fábricas, a $\mathrm{C}$, e em uma determinada atividade, levando em consideração sua magnitude e complexidade.

Dessa forma, trazendo uma visão geral das 3 fábricas, vale explicitar que a fábrica $A$ desenvolve serviços de galvanoplastia, a B também realiza esse mesmo serviço, além de produzir produtos brutos por estamparia, e a $\mathrm{C}$ realiza todos esses processos, além da fabricação de brutos por fundição de metais.

De modo geral, as fábricas têm mais de 2.000 clientes cadastrados, podem produzir mais de 1 milhão de peças brutas ao mês, com variação de 1 a 50 tipos de peças diferentes, sendo que a quantidade por tipo pode variar de $200 \mathrm{a}$ 3000 unidades.

Os processos produtivos de forma sucinta são: vendas, recebimento, estamparia, fundição de baixa fusão, fundição de alta fusão, limpeza, preparação de peças para galvanoplastia, galvanoplastia, montagem, aplicação de ródio e betume, acabamentos, inspeção, conferência e expedição. Esses processos fabris se assemelham aos descritos em 2014 por Zambon e Anuniação referente ao setor de bijuteria (Zambon e Anunciação 2014).

O serviço terceirizado informal é chamado de "Rua" e todas as fábricas o utilizam em diferentes processos, tais como para tarefas ligadas a montagem e tratamento de superfícies, entre outros. A terceirização é utilizada como estratégia para flexibilizar tanto a força de trabalho, como a estrutura organizacional da empresa visando especialmente a redução de custos. Essa 
informalidade, criada ao redor das empresas que se utilizam de terceiros, pode engendrar modos e condições precárias de trabalho (Krein et al., 2018; Antunes e Druck, 2013).

O prazo de entrega de pedidos para clientes é de, no máximo, 15 dias, sendo constantes as cobranças para encurtar esse período, demandando muitos encaixes na fabricação bem como uma incessante busca por antecipação. Outro aspecto que revela este ritmo intenso aparece na incapacidade de previsão diária e desconhecimento da quantidade de tarefas demandadas, uma vez que será de acordo com a variabilidade dos tipos de peças e das características dos serviços requisitados pelos clientes.

O produto bruto, que serve como matéria-prima na galvanoplastia, pertence ao cliente e está provisoriamente na empresa, demandando controle rígido (registros escritos e fotografias) no sentido de criar evidências durante todo o processo, que permitam sua rastreabilidade. Características relevantes sobre qualidade são avaliadas na beleza, nas superfícies bem-acabadas e brilho das peças, na rapidez na entrega e na confiança do cliente. Esta confiança está relacionada com histórico vivenciado entre fábrica e cliente, e na aplicação correta de metais preciosos sobre as peças.

Assim, a rotina de trabalho é marcada por imprevistos, também percebidos nos relatos de obediência aos clientes, tentando-se atender a todas as solicitações, tais como encaixes de outros serviços solicitados diariamente $\mathrm{e}$ cobranças constantes. Esses encaixes de pedidos de certos clientes geram atrasos de outros e, portanto, demandam mais negociações dos funcionários. Todos os pedidos são requisitados e/ ou comprados pelas áreas reconhecidas nas fábricas como de Entrada (Recebimento/ Vendas/ Análises) e são finalizados na área de Saída (Montagem/ Inspeção/ Conferência/ Expedição). As líderes desses grupos, compostos exclusivamente por mulheres, se responsabilizam por todos os processos que são desenvolvidos bem como pela entrega, absorvendo o gerenciamento das adversidades que podem impactar nos produtos e clientes.

A predominância de produção puxada, de acordo com demandas novas no decorrer de todo o dia, a diversidade de produtos, de serviços e de clientes, a pressão por 
qualidade e por tempo, com constante e rotineiro encaixe de pedidos foram dificuldades referidas e descritas nos processos das empresas, principalmente na fábrica C. Essas características fazemse mais presentes nas tarefas de maior contato com clientes, demandando diversas estratégias de negociação externa (junto ao cliente) e interna (com os(as) trabalhadores(as)) no sentido de conseguir agilidade para atender aos prazos negociados e renegociados. Por isso, com o reconhecimento de serem atividades chaves nas fábricas e consenso dos interlocutores foram realizadas observações abertas nessas áreas de trabalho.

A fábrica $\mathrm{C}$ concentra todas as modalidades de fabricação de semijoias e na atividade de "Vendas", na prática, o(a) trabalhador(a) detém as responsabilidades de vendas presenciais, por telefone e por internet, recebimento e análises de encomendas, fidelização de clientes, controle de sistemas, gerenciamento de produção, expedição e logística, orçamentos, precificações, serviços pós-venda, entre outros. Observou-se que esta atividade se torna determinante para a empresa porque nela se concentra o volume, ritmo e organização da produção, além da fidelização de clientes.

\section{A Riqueza Do Trabalho Na Produção De Semijoias}

A partir das entrevistas, observações, registros e cronologias da atividade, optamos por analisar a fábrica $\mathrm{C}$ que apresenta de forma concentrada todos os desafios vivenciados pelas demais fábricas.

Ao observar o trabalho da atividade de Vendas, na fábrica $\mathrm{C}$, foi possível perceber a rotina da trabalhadora responsável, descrita a seguir: ela se mantém predominantemente visualizando a tela e interagindo com o computador, simultaneamente atende ou manuseia o telefone e dialoga com a recepcionista na sala ao lado. Ao mesmo tempo, manuseia caixas, sacolas e monta peças. Estas atividades são interrompidas com a chegada de clientes na empresa, os quais ela atende na mesa de reunião de sua sala ou na sala de pronta-entrega.

Ela relata que está em constante contato com os líderes de produção para saber como está o andamento de pedidos e seus estoques. Estes se referem a peças para montagem 
das fundições, nas compras/montagem estoque de componentes e partes semiprontas, pois no caso da Estamparia e Galvanoplastia produzem exclusivamente por demanda. Aponta igualmente, que a experiência de tantos anos de trabalho na empresa (em torno de 30 anos), permite que consiga fazer previsão de pedidos à produção antecipando uma futura falta de produtos na pronta-entrega e na loja da cidade (da qual a empresa é sócia). Relata que nestes casos, a quantidade básica requisitada varia de 30 a 500 mil peças. Acrescenta que em um mesmo pedido, comumente, há produtos de Fundição Alta e Baixa, Estamparia e Montagem, o que demanda planejar as ações do(s) setor(es) de forma a sincronizar o tempo para todas as peças estarem prontas no mesmo dia de entrega.

Um dia de rotina desta trabalhadora pode ser descrito da seguinte forma: Todas as manhãs, a trabalhadora recebe e-mail da loja (gerado automaticamente pelo sistema informatizado da loja) sobre as vendas do dia anterior, que $\log 0$ as insere manualmente no sistema da fábrica. $\mathrm{O}$ uso constante do computador ou telefones (e-mail, ligação telefônica e WhatsApp e Skype), são meios pelos quais ela negocia preços, produção, prazos e envia fotos dos produtos. Estes meios lhe permitem enviar mensagens escritas ou de áudio e se comunicar com outras trabalhadoras da área administrativa. Aponta que utiliza além do telefone fixo da empresa, outros três telefones celulares para trabalhar. Ao mesmo tempo em que atende os clientes que se dirigem pessoalmente até a empresa.

Outra atividade desta trabalhadora é o controle das peças e produtos que ela rastreia em diferentes fases da produção, ultrapassando as barreiras geográficas da empresa (Ilustração 1). Chama a atenção o conhecimento que ela possui em relação ao lugar em que se encontram os diferentes produtos e peças dentro da fábrica, sendo crucial para a entrega de produtos e, fora da fábrica, com os fornecedores de matéria-prima, peças e produtos em trânsito e, no serviço de Rua, além dos produtos à venda na loja.

Ilustração 1 Atividade de Vendas (fábrica C): Localização de peças e produtos, interfaces e meios de comunicação 
Periódico do Núcleo de Estudos e Pesquisas sobre Gênero e Direito

Centro de Ciências Jurídicas - Universidade Federal da Paraíba

V. 8 - No 05 - Ano 2019

ISSN | 2179-7137 | http://periodicos.ufpb.br/ojs2/index.php/ged/index

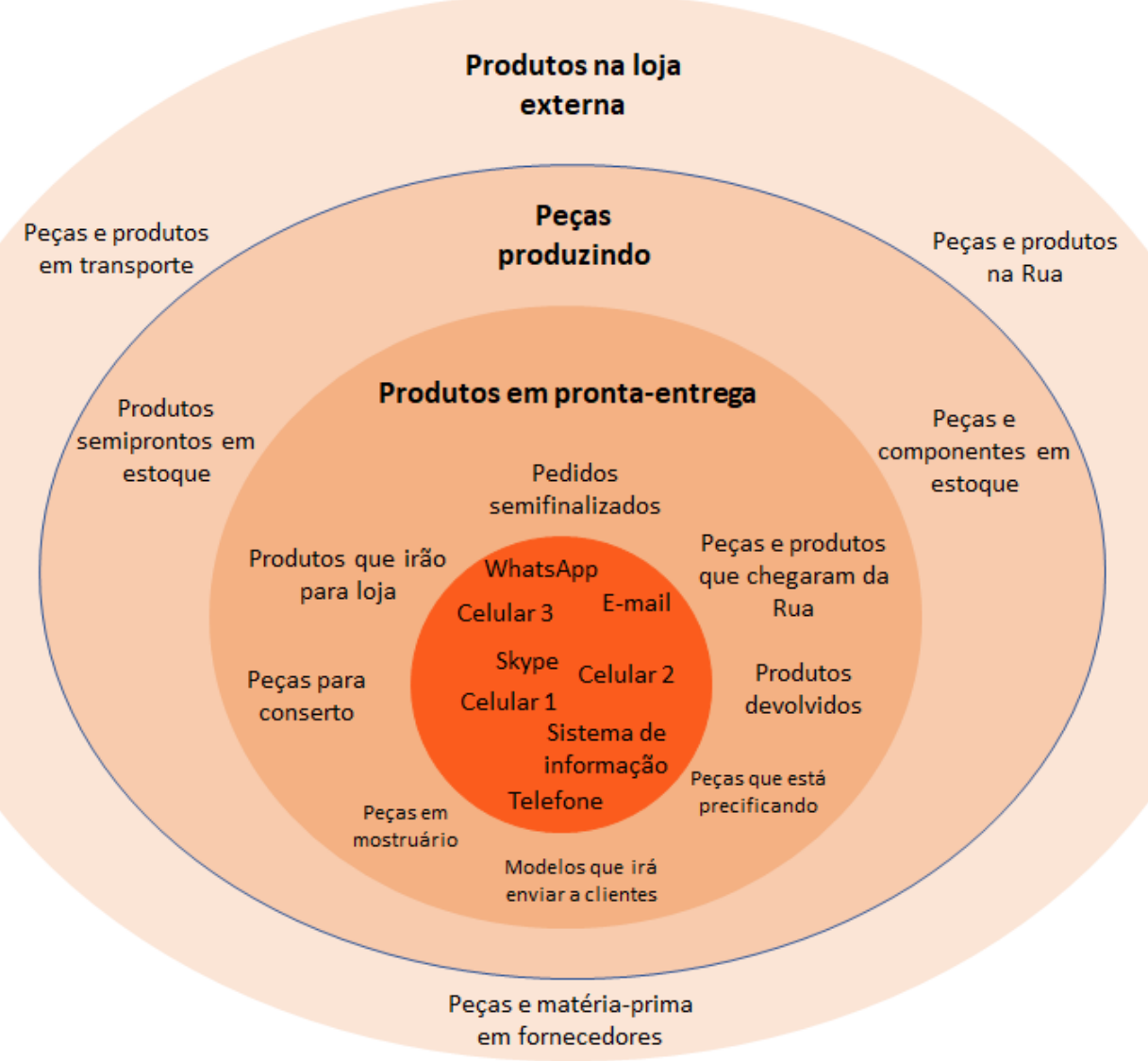

Legenda: "Rua": expressão usada para designar o trabalho de terceiros

Fonte: Elaboração própria (2019)

\section{Conforme o relato da}

funcionária, corroborado pelas observações da atividade, é preciso desenvolver grande habilidade para lidar com as múltiplas frentes exigidas para a execução das tarefas, demandando diferentes competências, para além do uso da criatividade. Durante as vendas a operadora digita de memória os códigos que ela mesma gerou anteriormente no sistema. Dito de outra forma, é ela quem cria códigos e preços no sistema para todos os novos produtos, quase que diariamente. Segue um breve fluxograma demonstrando a sequência de tarefas na área de Vendas:

Fluxograma 1 Tarefas na área Vendas, Fábrica C 


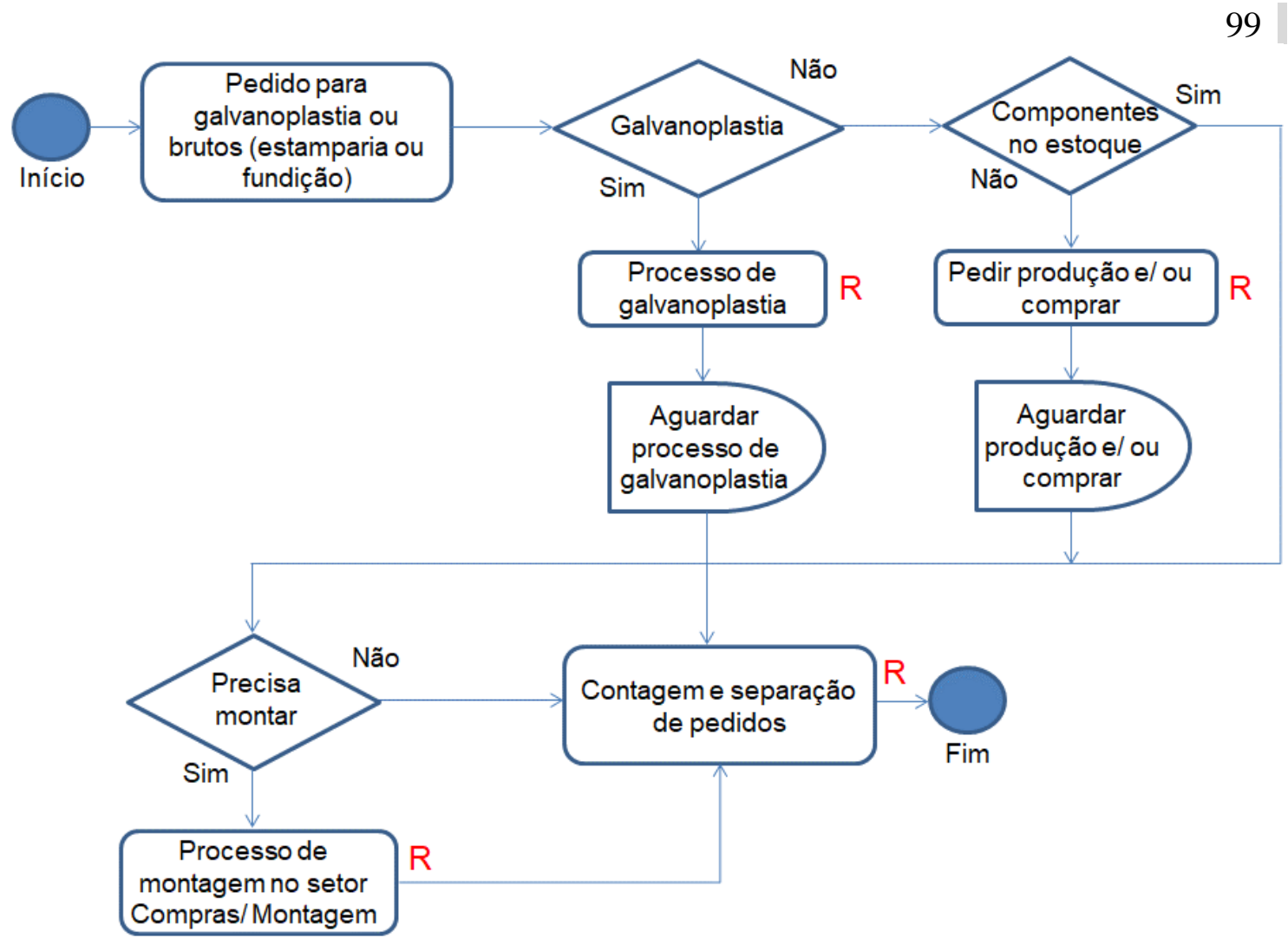

Legenda: "R": Rua expressão usada para designar o trabalho de terceiros

Fonte: Elaboração própria (2019)

Seu trabalho envolve a produção como um todo e o serviço de Rua, representado no fluxograma pela letra " $R$ " na cor vermelha, que está presente na maior parte das etapas. A sua atuação pode ser requisitada em outras funções como na preparação para o banho, na montagem, colagem $\mathrm{e}$ cravação, na solda, em acabamentos como "craquelar" e "diamantar", até o "encartelamento" final, entre outros. Cabe destacar que, a tarefa de encartelamento é conhecida como a primeira realizada pelas crianças em seu processo de inserção no trabalho (Vendramin, 2017).

Quando perguntamos sobre prazos, a trabalhadora diz que é "o quanto antes", o que mostra que a ação deve ser cumprida de imediato, não havendo um tempo pré-determinado. Em relação ao estoque, que também faz parte da sua função, segundo ela deve acompanhar os produtos em relação à oferta e demanda, determinando assim os produtos que pouco saem para serem colocados em promoção na loja externa. Cabe apontar que, há exigência de tomadas de decisão rápidas e efetivas, o 
que demanda um bom conhecimento e experiência para avaliar o produto que deve manter em estoque e aquele que não é produtivo para a empresa. Ao mesmo tempo, é preciso fazer orçamentos, de acordo com a demanda de cada cliente independente da variabilidade no pedido e, formar produtos possíveis dentro de preços exatos.

$$
\text { É preciso manter a }
$$
fidelização não só dos clientes em relação aos prazos de entrega e qualidade dos produtos, mas também dos próprios trabalhadores de Rua, sobretudo com aqueles que realizam trabalhos específicos e de boa qualidade, como por exemplo os que fazem solda.

A atividade da trabalhadora de "Vendas" então concentra as responsabilidades, não apenas de vender, mas de analisar produção e pedidos de encomendas, distribuir as tarefas entre os trabalhadores (internos e externos), controlar os tempos, custos e preços, constituindo-se então em um trabalho de gestão integrada.

$\mathrm{Na}$ ilustração a seguir (Ilustração 2) visualiza-se um resumo das relações estabelecidas internamente e externamente na atividade de Vendas. 
Ilustração 2 Desenho dos fluxos de processos de vendas até clientes da Fábrica C

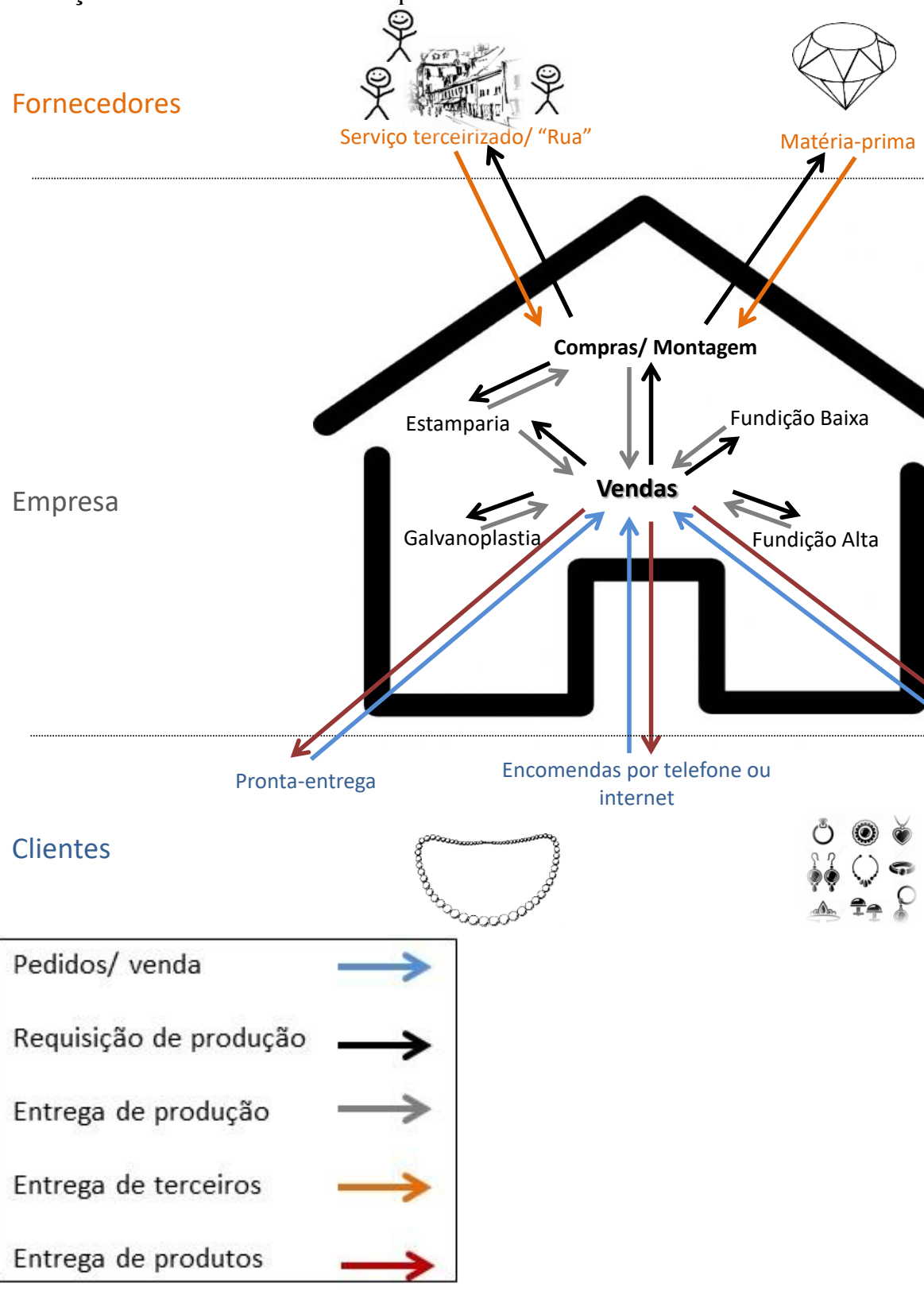

Fonte: Elaboração própria (2019)

$\mathrm{Na}$ cronologia da atividade de Vendas, realizada durante uma jornada integral de trabalho, foram feitos 183 registros, cada qual com 1 ou poucos minutos de diferença entre eles, permitindo ainda visualizar que ações/atividades simultâneas são constantes. Foi observado o trabalho operacional com peças, ocultado na descrição inicial sobre as tarefas, e a relevância de se gerenciar as quantidades de produtos, além das interfaces e negociações com os outros trabalhadores (internos e externos), juntamente com 
Periódico do Núcleo de Estudos e Pesquisas sobre Gênero e Direito

Centro de Ciências Jurídicas - Universidade Federal da Paraíba

V. 8 - No 05 - Ano 2019

ISSN | 2179-7137 | http://periodicos.ufpb.br/ojs2/index.php/ged/index

uso de sistema computadorizado e de diferentes dispositivos eletrônicos.

Os principais achados na cronologia da atividade, em termos de frequência e duração, são atividades realizadas em $50 \%$ a $82 \%$ das vezes simultaneamente com outras ações de trabalho. Descreveu-se ainda, quais pessoas estavam envolvidas (clientes e pessoas internas ou externas à fábrica) e quais interfaces (manejo de produtos, telefone e ou computador/sistema), bem
102

como quais eram as estratégias/enfrentamentos realizados (estoques e reposições, negociação interna e entrega/prazos).

Refletindo assim sobre as diferentes situações e devidas questões de análise que a própria trabalhadora se coloca, foi possível perceber a intrincada gama de decisões que ela precisa compatibilizar, como no caso da galvanoplastia e da produção de brutos (Ilustrações 3 e 4).

Ilustração 3 Alguns questionamentos feitos pela trabalhadora de Vendas para gerenciar a produção em Galvanoplastia na Fábrica C

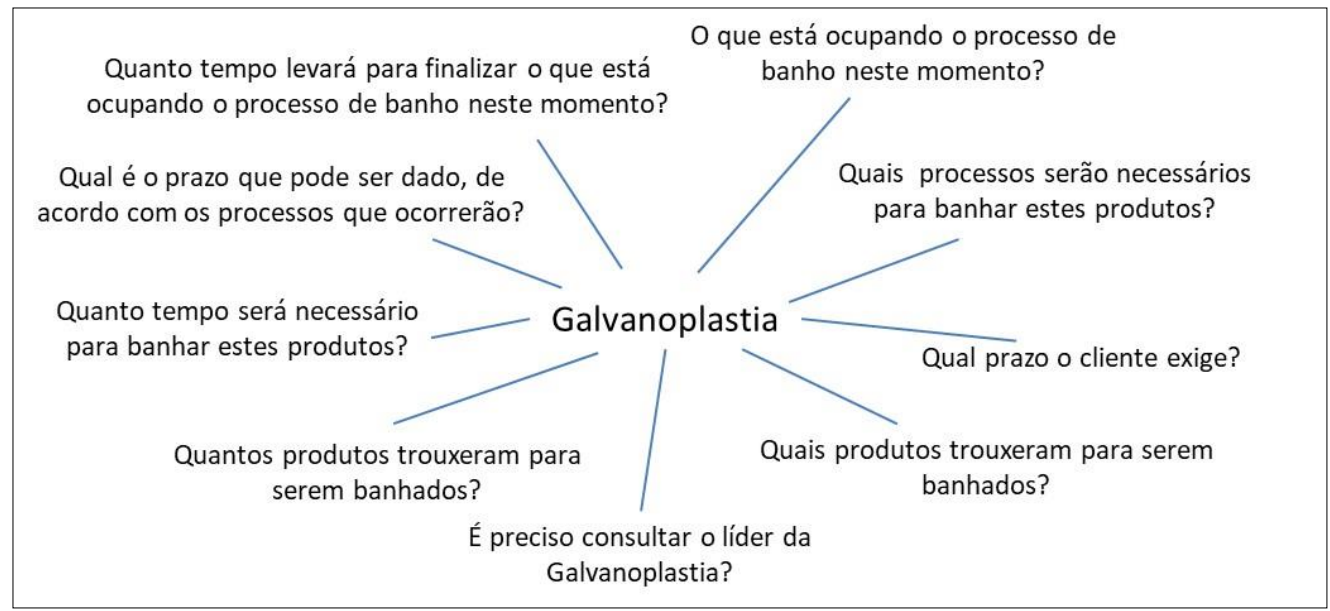

Fonte: Elaboração própria (2019) 
Periódico do Núcleo de Estudos e Pesquisas sobre Gênero e Direito

Centro de Ciências Jurídicas - Universidade Federal da Paraíba

V. 8 - No 05 - Ano 2019

ISSN | 2179-7137 | http://periodicos.ufpb.br/ojs2/index.php/ged/index

Ilustração 4 Alguns dos questionamentos feitos pela trabalhadora de Vendas para gerenciar a produção de Brutos na Fábrica C

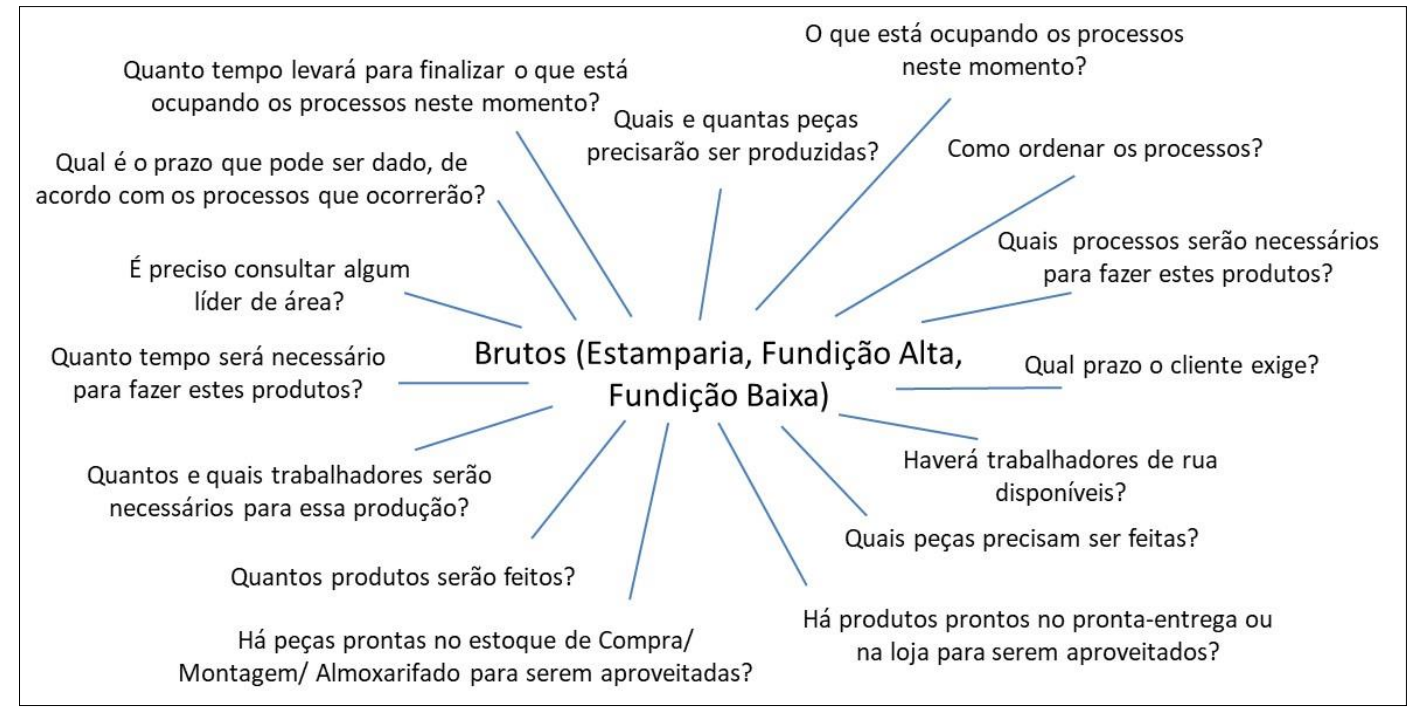

Fonte: Elaboração própria (2019)

Cada aspecto levado em conta no cotidiano de decisões da trabalhadora, guarda características próprias e simultaneamente abarca múltiplas diversidades, uma vez que não são apenas as combinações de produtos que mudam, mas os componentes disponibilizados pelos fornecedores também se alteram, trazendo novidades e descontinuando o fornecimento de peças antigas. Constatou-se então que essa atividade comporta capacidade de criação movida por meio da experiência, capacidade de gestão por meio de constantes análises e de estabelecer comunicação e relacionamentos favoráveis com os trabalhadores internos e externos à fábrica, bem como com os clientes.

A atividade denominada simplesmente como "Vendas" nas fábricas, contém muito além de seu significado semântico, representando ampla riqueza advinda da construção de conhecimentos essenciais que essas mulheres disponibilizam para 0 andamento da empresa de forma geral e que se mostra como determinante para a produção de semijoias. Esse conhecimento bem como a capacidade de saber se relacionar com diferentes atores e partes desse sistema de atividade extremamente complexo, com sua diversidade e incertezas (Morin, 2003), demandam competências de natureza 
bastante diversa, pois é necessário "saber fazer", "saber compreender", "saber julgar" e "saber ser" (Maggi, 2006). Uma verdadeira riqueza imaterial, escondida no cotidiano das fábricas e aparentemente pouco valorizada.

\section{Saberes E Arte Contidos Nas}

\section{Semijoias}

A história da joalheria compreende o trabalho e a criatividade de sucessivas gerações de artesãos no desafio de transformar materiais preciosos em ornamentos de elevado valor artístico. Os metais preciosos e as joias refletem o que se julga beleza e são considerados de estima material, mantendo-se a qualidade apreciada especialmente por brilho e resistência (IBGM, 2015).

As tarefas na produção de semijoias não são claramente especificadas, uma vez que cada peça é diferente da outra em tipo, formato, tamanho, presença de pedrarias, entre outros. Além disso, as fábricas recebem pedidos diários, não sendo possível predizer com antecedência o que será realizado, pois muitas vezes só se vê a peça que receberá a aplicação do ródio ou pintura com betume momentos antes de se iniciar o trabalho. Uma frase frequentemente expressada pelas trabalhadoras é: "Todo dia é uma surpresa". Sendo assim, frente a essa imprevisibilidade, a criação e tomada de decisão se tornam absolutamente necessárias.

É observada uma avaliação visual da semijoia ou contemplação por parte da trabalhadora ao receber as peças com as quais irá trabalhar, segurando-a em suas mãos. E em conversa, descobrese que cada uma tem seu jeito de fazer, cada uma tem seu modo de criação, apesar das cobranças de tempo e as regras impostas pela fábrica para a realização do trabalho, deixando em cada peça sua marca, sua individualidade.

Novos modelos de produtos são desenvolvidos pelos próprios (as) trabalhadores (as), sendo que um deles, do setor de fundição, é notadamente conhecido por suas criações. Ele desenha os modelos em um programa de computador e ao relatar como acontece esta atividade, ele contou entusiasmado, gesticulando: "-Eu vou tendo ideias, imagino como pode ficar! Começo a desenhar, vou mudando e vai saindo!". Essa criação ocorre de forma livre até o limite do que a máquina de fundição é 
capaz de produzir com a qualidade desejada.

Outro exemplo ocorre quando novos produtos são criados com objetivo de reaproveitar peças que não venderam, ou não saíram como imaginado para então poder compor outro produto. Para evitar desperdícios, as trabalhadoras inventam novas pulseiras, colares e brincos. Em uma visita, uma trabalhadora segurando algumas partes na mão e mostrando aqueles componentes disse: "Eu fico olhando, olhando... Faço outra coisa, volto e começo a montar. Se não gosto, deixo, desfaço e tento depois. Até eu achar que está ficando bom!”.

Esta criação nos lembra a arte e as reflexões de Bachelard em seu livro "O direito de sonhar", no qual ele aponta a planura na hegemonia da visão, ligada à desvalorização do trabalho manual, conhecido como papel de escravos na sociedade grega antiga, em oposição ao trabalho intelectual. Esse vício de ocularidade submete toda a imaginação à do tipo formal, não considerando a imaginação material. De acordo com o autor, a matéria é primitivamente rebelde e a mão está sempre contra ela, operando suas forças criadoras e, portanto, forças felizes. Bachelard se refere ao trabalhador-artista, sendo a matéria oportunidade de realização pessoal e incentivo à imaginação criadora ("centro de sonhos") e, também, o primeiro adversário do poeta da mão (Bachelard, 1985).

São assim expressados, nas criações, os registros dessas trabalhadoras das semijoias que mostram com satisfação o que consideram como seus inventos, sua própria arte. Como descrito por Bachelard, é no fazer, na própria manualidade, que o imaginário entra em conflito com a matéria, fazendo surgir um constante vai e vem de ideias até alcançar sua gênese material.

No entanto, essas criações são impulsionadas e recheadas de intenções de vendas e preocupações com preços, custos, prazos, tempos e tantos outros fatores que circundam o mundo técnico, o mundo que busca sua coisificação e esquece dos seres. Assim, com essas interpretações, que vieram à tona em observações de trabalho com semijoias de Limeira, evidenciam-se os sujeitos, sua criatividade, sua imaginação material por trás desses produtos focados na beleza e imergidos na era da técnica ${ }^{22}$. Embora as mazelas desse setor, como o trabalho infantil (Ferreira, 2005; Vilela e Ferreira, 2008; Vendramin, 2017; 
Lacorte et al. 2013) e os riscos relacionados ao meio ambiente ${ }^{3,24}$ e à saúde humana (Ferreira, 2018; Figueiredo, 2011) já tenham sido explicitados em outros estudos, nas fábricas estudadas evidenciou-se práticas seguras no tratamento das questões ligadas aos produtos químicos e poucas queixas relacionadas a problemas de saúde. O que vale dizer que a contaminação ambiental assim como as intoxicações, as lesões osteomusculares, os problemas de coluna, os riscos de acidentes aos quais estão submetidas essas trabalhadoras de maneira geral existem e são necessárias ações urgentes de assistência, prevenção e vigilância em saúde, mas nosso foco aqui está voltado para explicitar que há uma criação por parte dessas mulheres, que talvez até mesmo sirva de fator protetor contra o adoecimento, se deixarmos de adotar uma visão puramente fisicalista do trabalho (Dejours, 2005; Boyer, 2014).

E apesar desse tipo de trabalho com semijoias demandar profundo conhecimento, criatividade e análise crítica, sua invisibilidade está presente na distância que se coloca entre essas(es) trabalhadoras(es) e um designer, considerado profissional habilitado a desenvolver esses produtos por ter
106

estudo formal no assunto, por fazer pesquisa de mercado e seguir metodologias pré aceitas e por usufruir de um "processo criativo" (Llaberia, 2009). Ao desvelar essa riqueza artística por trás desses produtos e relembrando o contexto social da cidade de Limeira, se torna visível o desajuste entre a realidade dessa produção e o reconhecimento do trabalho nela envolvido.

Se a criatividade pode ser interpretada como atividade cognitiva que surge na produção de joias, ela também está presente na produção de semijoias, a qual se encontra envolta por condições limitantes e perturbações como aquelas advindas das constantes interrupções para atender aos clientes. Para se alcançar um produto dentro do esperado em termos de qualidade e prazo, cada ação leva em conta seus possíveis impactos no resultado, sendo assim delimitada por critérios de julgamento. Estes podem ser considerados indicadores de um sistema dinâmico no qual se procura alcançar estados estáveis frente a distúrbios. A habilidade da trabalhadora de semijoias é navegar nestes estados, mas minimizando riscos e custos e maximizando qualidade dos resultados. As inusitadas situações geram novas 
condições a serem superadas e assim como o espaço de arranjo se altera, novas soluções são necessárias e impulsionam outras possibilidades (Wisner, 2003; Baber et al., 2017).

Assim, se vê criatividade nas relações homem-tecnologia que criam interação entre o estado do material e a ação do trabalhador ${ }^{22}$. A técnica para Heidegger não seria um simples meio, mas um tipo de desenvolvimento, na esfera do conhecimento, algo de natureza poética. Vista assim, ela seria possibilidade de desencobrimento ou de desvelamento para a manifestação da verdade (Heidegger, 2006).

Entretanto, os resultados produtivos alcançados nas fábricas estudadas se devem, particularmente, à adoção de modelo organizacional descrito por Harvey (1992) como flexível, no que tange aos contratos, formas e processos de trabalho, assim como de mercados, produtos e padrões de consumo. Nesse modelo, ocorre o retorno dos sistemas de trabalho doméstico e familiar assim como da subcontratação, fazendo ressurgir práticas e trabalho de cunho patriarcal, feitos em casa que oneram ainda mais as mulheres. Inclusive algumas funcionárias levam sacolas com produtos a serem trabalhados em casa, objetivando renda extra. Sendo assim, a produção se caracteriza por um tecido complexo (Morin, 2003) de interações humanas e materiais que está em constante movimento, pressupondo a gestão da ordem, mas também da desordem para posterior criação de uma nova ordem, que por sua vez, também não será definitiva.

\section{Considerações Finais}

Esta pesquisa permitiu desvelar a natureza do trabalho na fabricação de semijoias em Limeira, explicitando as condições comuns às fábricas tanto na organização do trabalho quanto na diversidade de produtos e clientes.

A análise aprofundada na atividade de "vendas" possibilitou entender o sucesso da fabricação e os aspectos que a ligam à produção de externalidades negativas, especialmente as sociais, para além de explicitar a riqueza desse trabalho. Trabalho que se desenvolve na proximidade com a arte, demandando constante invenção, que se materializa em função do conhecimento adquirido, em particular por mulheres, que assumem cargos cuja nomenclatura 
não revela as atividades integradas de gestão e criação, exercidas sob diferentes constrangimentos.

No exercício das atividades dessas mulheres existe uma constante busca por antecipar o prazo de entrega e superar as expectativas dos clientes, fazendo pedidos adaptados e customizados, num ambiente de expressiva pressão temporal. Além do que, elas são responsáveis pela rastreabilidade diária dos produtos, frequentemente desafiadas devido ao altíssimo volume de peças minúsculas, muitas vezes na casa dos milhares, que necessitam passar por diferentes etapas e setores produtivos.

Esse estudo trouxe à tona a importância dos processos de decisão e de comunicação e interligação exercidos pelas trabalhadoras, com os diferentes interlocutores, bem como de seus conhecimentos declarativos (saber que) e procedurais (saber como) que se manifestam no saber fazer qualificado e que permite o desenvolvimento de estratégias sofisticadas de antecipações e retroações, evidenciando um trabalho que é também rico e criativo. Desvela-se que é por meio das competências, da experiência e do engajamento dessas mulheres artistas que reside o grande bem invisível e não valorizado da produção de semijoias de Limeira.

Por fim, a pesquisa permitiu ainda tornar clara a conexão do trabalho nas três fábricas com $\mathrm{o}$ trabalho terceirizado, evidenciando que muitas etapas dos processos são feitas externamente, pelo chamado trabalho de "Rua". O fato é que a "Rua" compreende em sua maioria o trabalho em domicílio, e esse trabalho informal está imbricado com aquele exercido dentro das fábricas, funcionando como sua extensão. No entanto, esta informalidade pode enredar famílias, e, em particular, jovens e crianças em condições de vulnerabilidade a exercer atividades que colocam em risco tanto o meio ambiente quanto a comunidade envolvida.

\section{Referências bibliográficas}

Antunes, Ricardo; Druck, Graça. A terceirização como regra? Rev TST. 2013;79(4):214-31.

Baber, Chris et al., What the jewelller's hand tells the jeweller's brain: tool use, creativity and embodied cognition. School of Engineering, University of Birmingham, Birmingham. Philosophy \& Technology, Dordrecht. 2017: 1-20. 
Bachelard, Gaston, O direito de sonhar. Lisboa: Difel; 1985.

Bouyer, Gilbert Cardoso, O problema do fisicalismo/cognitivismo na ergonomia e segurança do trabalho. Gestão \& Produção, 21(4), 691-706, 2014. Consultada a 25.02.2019, em: https://dx.doi.org/10.1590/0104$\underline{530 \times 845}$.

Brasil. Lei nº 13.610 , de 10 de janeiro de 2018. Confere ao Município de Limeira, no Estado de São Paulo, o título de Capital Nacional da Joia Folheada. Diário Oficial da União. 11 jan 2018; Seção 1:2. Consultada a 30.02.2018, em: http://www2.camara.leg.br/legin/fed/lei/ 2018/lei-13610-10-janeiro-2018786086-publicacaooriginal-154739pl.html.

Dejours, Christophe. O fator humano. Rio de Janeiro: FGV, 2005.

Ferreira, Ana Paula Sacone da Silva, Famílias inseridas no arranjo produtivo informal da produção de joias e bijuterias de Limeira, SP: a exposição ocupacional a contaminantes químicos em ambiente domiciliar [dissertação]. São Paulo: Faculdade de Saúde Pública da USP,
2018. doi: 10.11606/D.6.2018.tde30082018-150006.

Ferreira, Leda Leal, Sobre a Análise Ergonômica do Trabalho ou AET. Rev. bras. saúde ocup. [Internet]. 2015b. Jun [citado 2019. Abr 09] ; 40( 131 ): 8-11. Disponível em: http://www.scielo.br/scielo.php?script=s ci_arttext\&pid=S0303-

$76572015000100008 \& \operatorname{lng}=$ pt.

http://dx.doi.org/10.1590/0303-

7657ED0213115.

Ferreira, Marcos Antonio Libardi, Estudo de risco à saúde do trabalhador $\mathrm{e}$ ao meio ambiente na produção de joias e bijuterias de Limeira - SP. 186 f. Dissertação (Mestrado) - Engenharia de Produção, Faculdade de Engenharia, Arquitetura e Urbanismo, Universidade Metodista de Piracicaba; 2005.

Ferreira, Mário César, Ergonomia da Atividade aplicada à Qualidade de Vida no Trabalho: lugar, importância e contribuição da Análise Ergonômica do Trabalho (AET). Rev. bras. saúde ocup. 2015a. Jun. 40( 131 ): 18-29. Consultada a 09.04.2019, em : http://www.scielo.br/scielo.php?script=s ci_arttext\&pid=S0303- 


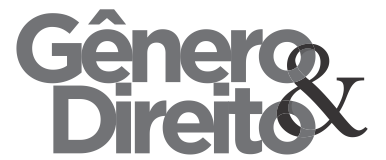

$76572015000100018 \& \operatorname{lng}=$ pt.

http://dx.doi.org/10.1590/0303-

$\underline{7657000074413}$.

Figueiredo, Vanessa Catherina

Neumann, Morbidades referidas por trabalhadoras que produzem joias folheadas em Limeira, SP. Rev. bras. saúde ocup. 2011. Dez. 36( 124 ): 247257. Consultada em 09.04.2019, em: http://www.scielo.br/scielo.php?script=s ci_arttext\&pid=S0303-

$76572011000200008 \& \operatorname{lng}=$ pt.

http://dx.doi.org/10.1590/S0303-

$\underline{76572011000200008 .}$.

Guérin François et al., Compreender o trabalho para transformá-lo: a prática da ergonomia. São Paulo: Edgard Blücher: Fundação Vanzolini; 2001.

Harvey, David, Condição pós-moderna. São Paulo: Loyola; 1992.

Heidegger, Martin, Sobre o problema do ser: o caminho do campo. São Paulo: Livraria Duas Cidades; 1969.

Heidegger, Martin, The question concerning technology. In: SCHARFF RC.; DUSEK, V. Philosophy of technology: the technological condition;
Periódico do Núcleo de Estudos e Pesquisas sobre Gênero e Direito Centro de Ciências Jurídicas - Universidade Federal da Paraíba

V. 8 - No 05 - Ano 2019

ISSN | 2179-7137 | http://periodicos.ufpb.br/ojs2/index.php/ged/index

an anthology. Oxford: Blackwell

Publishing Ltda, 2006.

Hirata, Helena; Kergoat, Danièle, Novas configurações da divisão sexual do trabalho. In:Cadernos de Pesquisa, v. 37, n. 132, p. 595-609, set./dez. 2007.

Instituto Brasileiro de Gemas e Metais Preciosos, O setor em grandes números. São Paulo; 2015. Consultada a 22/06/2017, em: http://ibgm.com.br/publicacao/o-setorem-grandes-numeros-2015/.

Jackson Filho, José Marçal; Maeno, Maria, Desenvolvimentos da Análise Ergonômica do Trabalho no Brasil no contexto da "desorganização do trabalho". Rev. bras. saúde ocup. 2015. Jun. 40 (131): 5-7. Consultada a 09.04.2019, em: http://www.scielo.br/scielo.php?script=s ci_arttext\&pid=S0303$76572015000100005 \& \operatorname{lng}=$ pt. http://dx.doi.org/10.1590/03037657ED0113115.

Kergoat, Danièle, Divisão sexual do trabalho e relações sociais de sexo. In: Hirata H, Laborie F, et al. Dicionário 
Crítico do Feminismo. São Paulo:

Edunesp, 2009.

Krein, José Dari et al., Flexibilização das relações de trabalho: insegurança para os trabalhadores - SP. Rev. do Tribunal Regional do Trabalho da $15^{\mathrm{a}}$ região, $\mathrm{n}$. $52,2018$.

Lacorte, Luiz Eduardo Cobra et al., Os nós da rede para erradicação do trabalho infanto-juvenil na produção de joias e bijuterias em Limeira - SP. Rev. bras. saúde ocup. 2013 Dez. 38 (128): 199215. Consultada a 09.04.2019, em: http://www.scielo.br/scielo.php?script=s ci_arttext\&pid=S0303-

$76572013000200009 \& \operatorname{lng}=\mathrm{pt}$.

http://dx.doi.org/10.1590/S0303-

76572013000200009.

Llaberia, Engracia Maria Loureiro da Costa, Design de joias: desafios contemporâneos. 188 f. Dissertação (Mestrado) - Design, Universidade Anhembi Morumbi, 2009.

Maggi, Bruno, Do agir organizacional: Um ponto de vista sobre o trabalho, o bem estar, a aprendizagem. São Paulo: Edgard Blücher, 2006.
111

Ministério de Minas e Energia, Anuário estatístico do setor de transformação de não metálicos, 2018. Consultada a 10.02.2019, em 2019 em: http://www.mme.gov.br/documents/113 8775/1732813/ANU\%C3\%81RIO+N\% C3\%83O-

METALICOS+2018_09.08.2018.pdf/53 de4d8a-bbf2-4196-b067-c0df241c1352.

Morin, Edgar, Ciência com consciência. 7 ed. Rio de Janeiro: Bertrand Brasil, 2003.

Salles, Fernanda Junqueira et al., The environmental impact of informal and home productive arrangement in the jewelry and fashion jewelry chain on sanitary sewer system. Environmental Science and Pollution Research. 2018;25(11):10701-13.

Serviço Nacional de Aprendizagem Industrial, Caracterização do setor de gemas, joias e metais preciosos no Brasil, perspectivas para inovação e desenvolvimento setorial. Série estudos setoriais. Prof. Hilton Manuel Dias Ribeiro. Brasília: Modelo SENAI de prospecção. 2011; 11. 
Sznelwar, Laerte Idal, Alain Wisner: O desenvolvimento da ergonomia e do pensamento sobre o "trabalhar". Travailler. 2006; 1(15):55-70.

Vendramin, Márcia Cristina Silva, Trabalho infantil em Limeira - SP: pesquisa com estudantes da rede municipal e estadual de ensino. $119 \mathrm{f}$. Dissertação (Mestrado) Interdisciplinar em Ciências Humanas e Sociais Aplicadas (ICHSA), área de concentração Modernidade e Políticas Públicas, Faculdade de Ciências Aplicadas, Universidade Estadual de Campinas; 2017.

Vidal, Renata de Queiroz Santana; Silvany Neto, Annibal Muniz, Trabalhadoras brasileiras: características socioeconômicas e ocupacionais e perfil de saúde, Brasil, 2003. Rev. bras. saúde ocup. 2009. Dez. 34 (120): 115-127.

Consultada a 09.04.2019, em: http://www.scielo.br/scielo.php?script=s ci_arttext\&pid=S0303-

$76572009000200003 \& \operatorname{lng}=$ en.

http://dx.doi.org/10.1590/S0303-

\section{3.}

Vilela, Rodolfo Andrade Gouveia, Ferreira, Marcos Antonio Libardi, Nem tudo brilha na produção de joias de
Limeira - SP. Produção. 2008; 18(1):183-194.

Wisner, Alain, A inteligência no Trabalho: textos selecionados de ergonomia. Brasília: Ministério do Trabalho; 2003.

Zambon, Anatonio; Anunciação, Pedro, Inteligência competitiva. Percepções de valor no setor da bijuteria. Revista portuguesa e brasileira de gestão. 2014;13(2):41-60

\section{Agradecimentos:}

À FAPESP pelo auxílio de pesquisa Processo 2014/25829-0 